Article

\title{
Thermochromism of Highly Luminescent Photopolymer Flexible Films Based On Eu (III) Salts Confined in Polysulfone
}

\author{
Mani Outis ${ }^{1}$, João Paulo Leal ${ }^{2}\left(\mathbb{D}\right.$, Maria Helena Casimiro ${ }^{3}\left[\right.$, Bernardo Monteiro ${ }^{4, *}$ (C) \\ and Cláudia Cristina Lage Pereira ${ }^{1, *(\mathbb{D})}$ \\ 1 LAQV-REQUIMTE, Departamento de Química, Universidade Nova de Lisboa, 2829-516 Caparica, Portugal; \\ m.hosseinzadeh@campus.fct.unl.pt \\ 2 Centro de Química Estrutural (CQE), DECN, Instituto Superior Técnico, Universidade de Lisboa, \\ Estrada Nacional 10, 2695-066 Bobadela, Portugal; jpleal@ctn.tecnico.ulisboa.pt \\ 3 Centro de Ciências e Tecnologias Nucleares (C2TN), Instituto Superior Técnico, Universidade de Lisboa, \\ Estrada Nacional 10, 2695-066 Bobadela, Portugal; casimiro@ctn.tecnico.ulisboa.pt \\ 4 Centro de Química Estrutural (CQE), DEQ, Instituto Superior Técnico, Universidade de Lisboa, \\ Estrada Nacional 10, 2695-066 Bobadela, Portugal \\ * Correspondence: bernardo.monteiro@ctn.tecnico.ulisboa.pt (B.M.); ccl.pereira@fct.unl.pt (C.C.L.P.)
}

Received: 27 October 2020; Accepted: 25 November 2020; Published: 27 November 2020

\begin{abstract}
Here we discuss the influence of two different cations on the emissive properties of the highly emissive $\left[\mathrm{Eu}(\text { fod })_{4}\right]^{-}$anion. The studied $\mathrm{Eu}(\mathrm{III})$ salts were $\left[\mathrm{C}_{16} \mathrm{Pyr}\right]\left[\mathrm{Eu}(\mathrm{fod})_{4}\right](\mathbf{1})$, and the previously reported [Chol] [Eu(fod $\left.)_{4}\right]$. $\mathrm{C}_{16} \mathrm{Pyr}$ stands for N-cetylpyridinium, Chol for cholinium and fod for 1,1,1,2,2,3,3-heptafluoro-7,7-dimethyloctane-4,6-dionate. $\mathbf{1}$ is classified as ionic liquid, with melting point close to $60^{\circ} \mathrm{C}$, and presented a luminescence quantum yield of $(\phi) 100 \%$. Ultrabright emissive photopolymers were obtained for the first time using polysulfone as the host matrix. The films were prepared with incorporation of $10 \%(w / w)$ of $\mathbf{1}$ and [Chol][Eu(fod) $\left.)_{4}\right]$ in the polymeric matrix, which improved its thermal stability. Additionally, the luminescence of CholEu(fod) $4 / \mathbf{P S U}$ presented a strong temperature dependence with a ratiometric thermal behavior.
\end{abstract}

Keywords: thermal behavior; lanthanide; $\beta$-diketonate; polysulfone; polymer films; europium (III), hybrid materials

\section{Introduction}

Carlos and co-workers reviewed recently and exhaustively the luminescence thermometry of lanthanide compounds applied as thermal probes for temperature determination in numerous biomedical implementations [1,2]. This research field has been widely explored in the last decade because of the enormous potential of luminescence thermometry particularly in nanotechnology and nanomedicine [3,4].

The determination of temperature in living cells is of paramount importance, as cancer cells are known for having higher temperatures than those of normal tissues due to the increased metabolic activity [5]. Among others, this is an example where conventional thermometry is not helpful, as this demands precise thermometry down to the nanoscale and the common thermocouples and thermistors are inappropriate below $10 \mu \mathrm{m}$ [2].

In $\mathrm{Eu}$ (III) doped systems, the ratio of the emission intensity between ${ }^{5} \mathrm{D}_{1} \rightarrow{ }^{7} \mathrm{~F}_{\mathrm{J}}$ and one of the emission bands from the ${ }^{5} \mathrm{D}_{0} \rightarrow{ }^{7} \mathrm{~F}_{1}$ or ${ }^{5} \mathrm{D}_{0} \rightarrow{ }^{7} \mathrm{~F}_{2}$ transitions has been used as a possible strategy for temperature sensing [6-13]. 
Here we describe a new approach that will allow the design of new ratiometric temperature sensors based on the highly emissive Eu (III) tetrakis-betadiketonate complexes and the correspondent hybrid materials using as host polysulfone, PSU, as the polymeric matrix. A temperature-dependent degree of asymmetry of the confined $\mathrm{Eu}$ (III) complex allows a remarkable modification in the intensity of the hypersensitive transition ${ }^{5} \mathrm{D}_{0} \rightarrow{ }^{7} \mathrm{~F}_{2}$, that reflects the temperature to which the complex is exposed.

The nature of the cations in $\left[\mathrm{Eu}(\beta \text {-diketonate })_{4}\right]^{-}$-based salts can have a strong influence on the structure of the anion and consequently on the optical properties of the complexes [14,15].

Beside the here presented $\beta$-diketonate Eu (III) complexes, other important group of lanthanide complexes incorporated into different hosts are those based on the carboxylate ligands. In the case of PEGDMA, poly(ethylene glycol dimethacrylate) hybrids, it was observed a decrease in quantum yield efficiency, $\Phi$, after Eu (III) complex incorporation which may result from the stronger interaction of high energy $\mathrm{C}-\mathrm{H}$ and $\mathrm{O}-\mathrm{H}$ oscillators, which significantly quenches the emission of $\mathrm{Eu}(\mathrm{III})$ [16].

Developments in polydopamine fluorescent nanomaterials have been recently reviewed by Wang and Li due to their unique physicochemical and biological properties. [17]

Other organic-inorganic hybrid materials, based on silica gel functionalized with DAPTS ([3-(2-aminoethylamino)propyl]trimethoxysilane), APTS ((3-aminopropyl)trimethoxysilane) and TAPTS (3-[2-(2-aminoethylamino)ethylaminopropyl]trimethoxysilane) and containing covalently linked Ln-EDTA complexes of Gd (III), Eu (III) and Tb (III), exhibited intense luminescence when excited between 280-370 nm. The luminescent brightness however is dependent of the combination of the $\beta$-diketonate ligand used as antenna and the Ln (III) ion coordinated to the EDTA ligand on the silica gel surfaces. For the $\mathrm{Eu}$ (III) ion, the brightest materials are those which contain tta (thenoyltrifluoroacetonate) and $\mathrm{dbm}$ (dibenzoylmethanoate) as the luminescence sensitizers, while for $\mathrm{Tb}$ (III) the brightest systems were found when bzac (benzoylacetonate) and acac (acetylacetonate) were used as ligands [18].

Polysulfones, also called polyaryl sulfones, are a class of polymers with high thermal, oxidative and hydrolytic stability. They are amorphous, transparent thermoplastics that can be molded, extruded, or thermoformed into a wide variety of shapes. Based on this feature, we proposed a new method for evaluating the thermo-sensitivity of Eu-based flexible films by using a ratiometric signal between the electric dipole transition band ${ }^{5} \mathrm{D}_{0} \rightarrow{ }^{7} \mathrm{~F}_{2}$ and the magnetic dipole transition ${ }^{5} \mathrm{D}_{0} \rightarrow{ }^{7} \mathrm{~F}_{1}$ for $\mathbf{1} / \mathrm{PSU}$ and CholEu(fod) 4 /PSU.

We will discuss how changes in the site symmetry of the Eu (III) complexes confined in PSU can be ratiometrically related with temperature to which the complex is exposed.

\section{Materials and Methods}

\subsection{Synthesis}

Reagent grade chemicals including Polysulfone (beads, average $\mathrm{M}_{\mathrm{n}} \sim 22,000$ by $\mathrm{MO}$, ref.: 182443 ), were obtained from Aldrich and used without further purification. All solvents for spectroscopic studies were of spectroscopic grade (Aldrich) and used without further treatment.

$\left[\mathrm{C}_{16} \mathbf{P y r}\right]\left[\mathrm{Eu}(\mathbf{f o d})_{4}\right]$ (1): 4.1 equivalents (eq.) of $\mathrm{NaOH}(0.090 \mathrm{~g}, 1.119 \mathrm{mmol}, 50 \%$ w/w aqueous solution) were added to an ethanol solution of 4.1 eq. of Hfod $(0.331 \mathrm{~g}, 1.119 \mathrm{mmol})$ and left stirring for $2 \mathrm{~h}$. 1 eq. of $\mathrm{EuCl}_{3} \cdot 6 \mathrm{H}_{2} \mathrm{O}(0.100 \mathrm{~g}, 0.273 \mathrm{mmol})$ was then added to the reaction mixture and the resulting solution left stirring for $2 \mathrm{~h}$ followed by the addition 1 eq. of $\mathrm{N}$-cetylpyridinium chloride monohydrate $(0.098 \mathrm{~g}, 0.273 \mathrm{mmol})$. After $1 \mathrm{~h}$ the solvent was removed under low pressure. To remove the $\mathrm{NaCl}$, the solid obtained was redissolved in $\mathrm{CH}_{2} \mathrm{Cl}_{2}$ and the salt was removed by filtration. The pure compound was obtained as a powder after solvent evaporation, at room temperature with a yield of ca. $80 \%$. Calculated Analysis (Anal. Calcd.) for $\left[\mathrm{C}_{21} \mathrm{H}_{38} \mathrm{~N}\right]\left[\mathrm{Eu}\left(\mathrm{C}_{10} \mathrm{H}_{10} \mathrm{O}_{2} \mathrm{~F}_{7}\right){ }_{4}\right]: \mathrm{C}, 44.75$; $\mathrm{H}, 4.80 ; \mathrm{N}, 0.86 \%$. Experimental; C, 44.69; H, 4.91; N, 0.81\%. ${ }^{1} \mathrm{H}-\mathrm{NMR} \delta$ (ppm): 15.29 (s, $\left.{ }^{4} \mathrm{H}-\mathrm{C}_{16} \mathrm{Pyr}\right)$, $10.68\left(\mathrm{~s},{ }^{2,6} \mathrm{H}-\mathrm{C}_{16} \mathrm{Pyr}\right), 7.29$ (s, $\left.{ }^{3,5} \mathrm{H}-\mathrm{C}_{16} \mathrm{Pyr}\right), 5.29$ (s H $\mathrm{H}_{\alpha}$ fod), 3.29 (t, $\left.\alpha-\mathrm{CH}_{2}-\mathrm{C}_{16} \mathrm{Pyr}\right), 2.39$ (t, $\left.\beta-\mathrm{CH}_{2}-\mathrm{C}_{16} \mathrm{Pyr}\right)$, 1.96 ( $\left.\mathrm{t}, \gamma-\mathrm{CH}_{2}-\mathrm{C}_{16} \mathrm{Pyr}\right), 1.79$ ( $\left.\mathrm{m}, \mathrm{CH}_{2}-\mathrm{C}_{16} \mathrm{Pyr}\right), 1.35$ (m, $\left.\mathrm{CH}_{2}-\mathrm{C}_{16} \mathrm{Pyr}\right), 0.88$ (t, $\left.\mathrm{CH}_{3}-\mathrm{C}_{16} \mathrm{Pyr}\right)$. ESI-MS (m/z): $304\left[\mathrm{C}_{21} \mathrm{H}_{38} \mathrm{~N}\right]^{+}$(Figure S1), $1333\left[\mathrm{Eu}\left(\mathrm{C}_{10} \mathrm{H}_{10} \mathrm{O}_{2} \mathrm{~F}_{7}\right)_{4}\right]^{-}$(Figure S2). 
[Chol][Eu(fod) $)_{4}$ ]: Equal to 1 but using 1 eq. of $\mathrm{CholCl}(0.038 \mathrm{~g}, 0.273 \mathrm{mmol})$. Anal. Calcd. for $\left[\mathrm{C}_{5} \mathrm{H}_{14} \mathrm{NO}\right]\left[\mathrm{Eu}\left(\mathrm{C}_{10} \mathrm{H}_{10} \mathrm{O}_{2} \mathrm{~F}_{7}\right)_{4}\right]$ : C, 36.67; H, 3.70\%. Experimental; $\mathrm{C}, 36.61 ; \mathrm{H}, 3.98 .{ }^{1} \mathrm{H}-\mathrm{NMR} \delta$ (ppm): 5.51 ( $\mathrm{H}_{\alpha}$ fod), $4.03\left(\mathrm{~m},-\mathrm{CH}_{2} \mathrm{Chol}\right), 3.52\left(\mathrm{~m},-\mathrm{CH}_{2} \mathrm{Chol}\right), 3.26\left(\mathrm{~s},-\mathrm{CH}_{3} \mathrm{Chol}\right), 0.7\left(\mathrm{~s},-\mathrm{CH}_{3}\right.$ fod).

$\left[\mathrm{C}_{16} \mathrm{Pyr}\right]\left[\mathrm{Eu}(\mathrm{fod})_{4}\right] /$ polysulfone (1/PSU): Polysulfone $(0.0568 \mathrm{~g})$ and $\left[\mathrm{C}_{16} \mathrm{Pyr}\right]\left[\mathrm{Eu}(\mathrm{fod})_{4}\right](0.0057 \mathrm{~g})$ were dissolved with stirring in a closed vial with $5 \mathrm{~mL} \mathrm{CH}_{2} \mathrm{Cl}_{2}$. The doped membrane was obtained by leaving the resulting solution evaporating overnight in a loosely closed petri dish at a controlled temperature of $21^{\circ} \mathrm{C}$. 1/PSU membrane was collected from the petri dish and used without any further treatment. Thickness: $0.01 \mathrm{~mm}$.

[Chol][Eu(fod) $)_{4}$ ]/polysulfone: Equal to 1/PSU but using $0.0593 \mathrm{~g}$ of polysulfone and $0.0059 \mathrm{~g}$ of [Chol][Eu(fod $\left.)_{4}\right]$. Thickness: $0.01 \mathrm{~mm}$.

\subsection{Methods}

Microanalyses for $\mathrm{C}$ and $\mathrm{H}$ were carried using a Thermo Finnigan-CE Instruments Flash EA 1112 CHNS series. FT-IR spectra (range $4000-400 \mathrm{~cm}^{-1}$ ) of the europium salts were collected as $\mathrm{KBr}$ pellets (FT-IR grade, Sigma-Aldrich, St. Louis, MO, USA) averaging 64 scans with a maximum resolution of $4 \mathrm{~cm}^{-1}$ using a Thermo Scientific Nicolet iS50 FT-IR spectrometer (Thermo Scientific, Waltham, MA, USA). Analysis of the heated sample was performed by heating previously a $\mathrm{KBr}$ pellet containing 1 or 2 in an oven. The membranes, $\mathbf{1 / P S U}$ and $\left[\mathbf{C h o l ]}\left[\mathbf{E u}(\mathbf{f o d})_{4}\right] / \mathbf{P S U}\right.$, were collected using the same conditions as the Eu-salts but in ATR mode averaging 8 scans.

Spectrometry (ESI-MS). ESI-MS was performed using a Bruker HCT quadrupole ion trap mass spectrometer (Bruker, Bremen, Germany). Sample solutions $\left(\sim 10^{-5} \mathrm{M}\right.$, acetonitrile) were injected to the ESI source at a flow rate of $150 \mathrm{~mL} \cdot \mathrm{min}^{-1}$. The capillary temperature was set to $250{ }^{\circ} \mathrm{C}$ and $\mathrm{N}_{2}$ (cover gas) to a flow rate of $2 \mathrm{~L} \cdot \mathrm{min}^{-1}$. Both positive and negative modes were used.

The thickness of the membranes was measured on several points of strips of the prepared membranes with a Mitutoyo thickness gauge meter (Mitutoyo, Kawasaki, Japan) with a $0.01 \mathrm{~mm}$.

TGA curves were obtained with samples $(\sim 8 \mathrm{mg})$ in Aluminum crucibles using a thermogravimetric analyzer TA Instruments Q500 (TA Instruments, New Castle, PA, USA), with a heating rate of $10^{\circ} \mathrm{C} \cdot \mathrm{min}^{-1}$.

Luminescence spectra were measured in a SPEX Fluorolog-3 Model FL3-22 spectrofluorimeter using $1 \mathrm{~nm}$ slits. The excitation wavelength varied between 344 and $354 \mathrm{~nm}$. Lifetime measurements were run on a LKS.60 ns laser photolysis spectrometer from Applied Photophysics, with a Brilliant Q-Switch Nd:YAG laser from Quantel, using the second harmonic $\left(\lambda_{\text {exc }}=355 \mathrm{~nm}\right.$, laser pulse half-width equal to $6 \mathrm{~ns}$ ). Luminescence quantum efficiencies were measured by the absolute method with an Integrated Sphere. All spectra were corrected with correction functions provided by the supplier following standard procedures. For the luminescence quantum yield determination we used equations 8 and 9 of Ref. [19].

Luminescence decays were studied using a LS45-Perkin-Elmer spectrofluorometer in a time-drive mode using a pulsed xenon lamp, performing 2 measurements to confirm the repeatability.

Emission decays were preformed setting the spectral resolution for $2 \mathrm{~nm}$, using a perpendicular geometry relative to the laser excitation and averaging 2-10 measurements for each emission wavelength according to the emission intensity of the sample. Luminescence decay traces for each wavelength were analyzed using least-squares fittings of the experimental data, using Solver from Microsoft Excel. Luminescence studies with variable temperature was performed using an optical fiber focused in the sample that was heated on a thermostatized heating plate (Argolab, Capri, Italy), over a temperature range from 25 to $110^{\circ} \mathrm{C}$.

\section{Results}

$\mathrm{Eu}(\mathrm{III})$, as most lanthanides, have electronic excited states which radiatively decay to the ground state. The most studied lanthanides, in terms of luminescence, are Eu (III), with red luminescence, and $\mathrm{Tb}$ (III) with green luminescence, whose excited states are ${ }^{5} \mathrm{D}_{0}(580 \mathrm{~nm})$ and ${ }^{5} \mathrm{D}_{4}(490 \mathrm{~nm})$, respectively. Generally, for a higher degree of symmetry around Eu(III) center, the simpler is the emission spectrum, due to the simpler line splitting [20,21]. 


\subsection{Luminescence of $\left[\mathrm{Eu}(\mathrm{fod})_{4}\right]^{-}$as a Function of the Counter-Cation and Temperature in the Solid State}

The excitation spectrum of 1 was monitored within the Eu(III) ${ }^{5} \mathrm{D}_{0} \rightarrow{ }^{7} \mathrm{~F}_{2}$ transition maxima and was completely dominated by a broad band ranging in the UV (ca. 320-400 nm) with maximum of $320 \mathrm{~nm}$ (Figure 1). This band is attributed to ligand-centered $\left(S_{1} \rightarrow S_{0}\right)$ transitions of the fod-diketonate ligand.

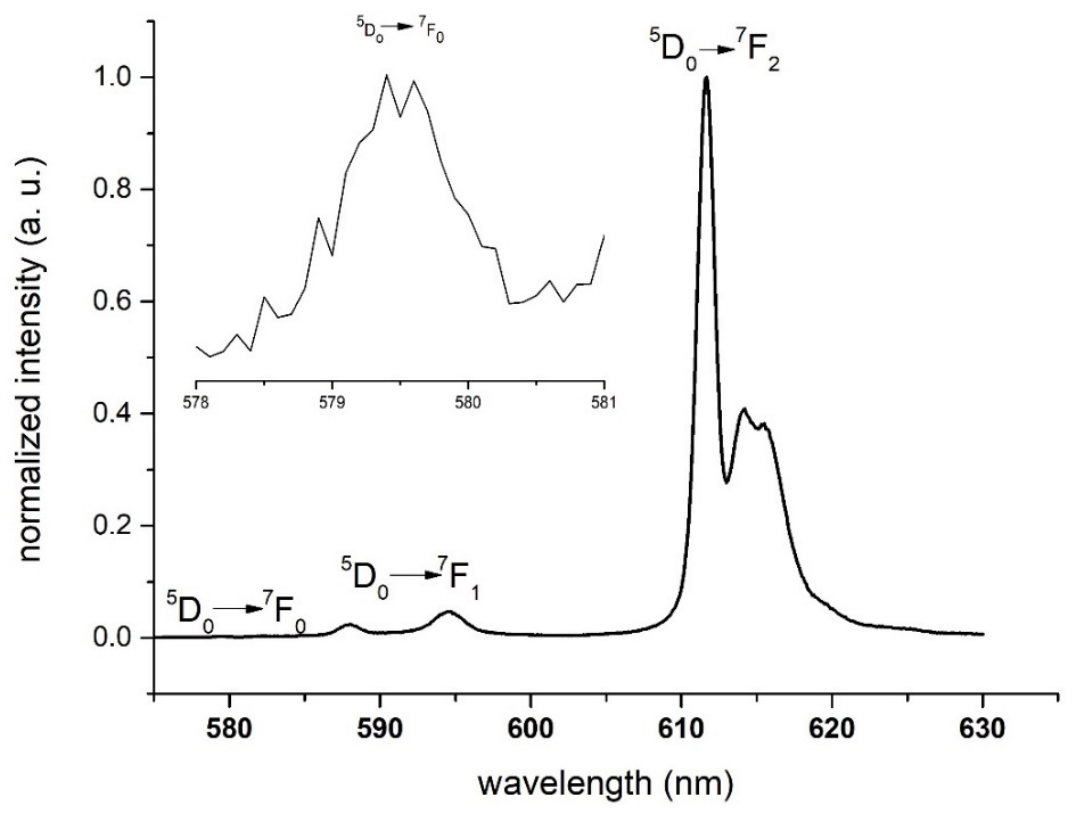

Figure 1. Normalized emission spectra of $\mathbf{1}$ (black line) relative to the most intense ${ }^{5} \mathrm{D}_{0} \rightarrow{ }^{7} \mathrm{~F}_{2}$ transition band at $25^{\circ} \mathrm{C}$ in the solid state with $\lambda_{\text {exc. }}=345 \mathrm{~nm}$. Inset magnification of ${ }^{5} \mathrm{D}_{0} \rightarrow{ }^{7} \mathrm{~F}_{0}$ transition band (wavelengh range $578-581 \mathrm{~nm}$ ).

The emission spectrum was recorded with the excitation wavelength set at $320 \mathrm{~nm}$. The transitions to the ${ }^{7} \mathrm{~F}_{5}$ and ${ }^{7} \mathrm{~F}_{6}$ levels were not observed due to limitation of the detection capacity of the spectrofluorimeter.

Figure 1 presents the most intense transitions observed for 1 and shows two electric dipole (ED) transitions; the ${ }^{5} \mathrm{D}_{0} \rightarrow{ }^{7} \mathrm{~F}_{0}$, with very low intensity and the ${ }^{5} \mathrm{D}_{0} \rightarrow{ }^{7} \mathrm{~F}_{2}$ transition very often the most intense band of the luminescence spectra. The ${ }^{5} \mathrm{D}_{0} \rightarrow{ }^{7} \mathrm{~F}_{1}$ transition is magnetic dipole dependent and its intensity is largely independent of the environment and can be considered in a first approximation to be constant. For this reason it is usually used to calibrate the intensity of the $\mathrm{Eu}(\mathrm{III})$ luminescence spectra [22]. It is not uncommon that the ${ }^{5} \mathrm{D}_{0} \rightarrow{ }^{7} \mathrm{~F}_{2}$ transition is 10 times more intense than the ${ }^{5} \mathrm{D}_{0} \rightarrow{ }^{7} \mathrm{~F}_{1}$ transition in $\mathrm{Eu}(\mathrm{III})-\beta$-diketonate complexes.

\subsubsection{Cation Effect}

The cation effect on the $\left[\mathrm{Eu}(\mathrm{fod})_{4}\right]^{-}$emission properties to be discussed here are $\mathrm{N}$-cetylpyridinium $\left(\left[\mathrm{C}_{16} \mathrm{Pyr}\right]^{+}\right.$, Scheme $\left.1 \mathrm{a}\right)$ and Cholinium $\left([\mathrm{Chol}]^{+}\right.$, Scheme $\left.1 \mathrm{~b}\right)$

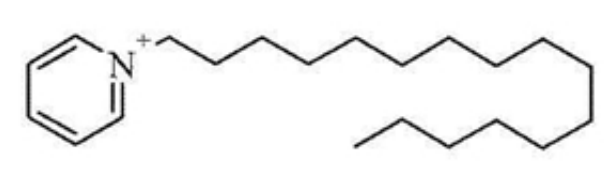

(a)<smiles>C[N+](C)(C)CCO</smiles>

(b)

Scheme 1. (a) N-cetylpyridinium and (b) Cholinium. 
For the $\left[\mathrm{P}_{6,6,6,14}\right]\left[\mathrm{Eu}(\mathrm{fod})_{4}\right]$ ionic liquid, a gradual color change was observed from light yellow to a deep red/purple around $80^{\circ} \mathrm{C}$. This was attributed to partial $\beta$-diketonate decomplexation, with concomitant establishment of a strong anion-cation interaction [14]. This color change, induced by heating and previously reported also for [Chol][Eu(fod $)_{4}$, was not observed for 1, that maintained its light-yellow color unaltered until melting at temperature close to $60^{\circ} \mathrm{C}$.

It was previously reported that the cations of $\left[\mathrm{Eu}(\beta \text {-diketonate })_{4}\right]^{-}$salts can have a strong influence on the structure of the anion and consequently on the optical properties of the complexes $[23,24]$. In this case, despite having the same coordination sphere around the $\mathrm{Eu}(\mathrm{III})$, the luminescence properties of $\mathbf{1}$ and [Chol] $\left[\mathrm{Eu}(\mathrm{fod})_{4}\right]$ are significantly different (Table 1 ) in terms of absolute emission quantum yield $(\Phi, \%)$, emission lifetime and ${ }^{5} \mathrm{D}_{0} \rightarrow{ }^{7} \mathrm{~F}_{2}$ transition band splitting (Figure 2).

Table 1. Emission lifetime ( $\tau, \mathrm{ms})$ and absolute emission quantum yield $(\Phi, \%)$ of $\mathbf{1}$ and [Chol][Eu(fod $\left.)_{4}\right]$.

\begin{tabular}{|c|c|c|}
\hline- & 1 & {$[\mathrm{Chol}]\left[\mathrm{Eu}(\mathrm{fod})_{4}\right][25]$} \\
\hline$\tau(\mathrm{ms})$ & 0.63 & 1.26 \\
\hline$\Phi(\%)$ & 100 & 81 \\
\hline
\end{tabular}

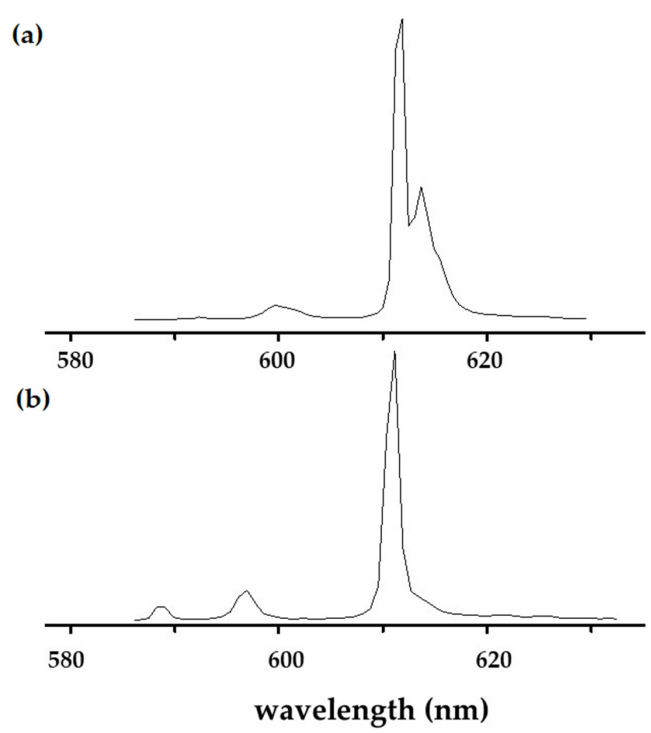

Figure 2. Normalized emission spectra of (a) 1 and (b) [Chol][Eu(fod) $\left.)_{4}\right]$, relative to the most intense ${ }^{5} \mathrm{D}_{0} \rightarrow{ }^{7} \mathrm{~F}_{2}$ transition band at $30{ }^{\circ} \mathrm{C}$ in the solid state.

Higher lifetime of the ${ }^{5} \mathrm{D}_{0}$ excited state (Table 1 ) is an indication of poorly efficient nonradiative relaxation processes due to the good shielding of the $\mathrm{Eu}(\mathrm{III})$, which is related, in this case, not only with the nature of the $\beta$-diketonate ligand, tetrakis-1,1,1,2,2,3,3-heptafluoro-7,7-dimethyloctane-4,6-dionate (fod), but also with the nature of the counter-ion.

Assuming residual anion-cation interactions at room temperature, an absolute quantum yield of $100 \%$ for 1 could be explained by the absence of any cation interaction with the "fod" ligands which is responsible for the antenna effect that increases the luminescence efficiency of Eu(III) center.

The emission profiles were measured at excitation wavelengths obtained from their corresponding excitation spectra, $345 \mathrm{~nm}$ for $\mathbf{1}$ and $340 \mathrm{~nm}$ for [Chol][Eu(fod) $\left.)_{4}\right]$.

Figure 2 presents the emission spectra recorded for 1 and [Chol][Eu(fod $\left.)_{4}\right]$ in the solid state, in the 575-630 nm spectral range, corresponding to the ${ }^{5} \mathrm{D}_{0} \rightarrow{ }^{7} \mathrm{~F}_{\mathrm{J}}(\mathrm{J}=1-2)$ transitions of $\mathrm{Eu}(\mathrm{III})$.

The most intense ${ }^{5} \mathrm{D}_{0} \rightarrow{ }^{7} \mathrm{~F}_{\mathrm{J}}$ transition is an electric dipole transition and its intensity and splitting are very sensitive to the local symmetry and the nature of the co-sensitizers.

The intensity ratio $R_{21}$, also known as the asymmetry ratio, indicates the degree of distortion from the inversion symmetry of the local environment around the Eu(III) ions [26]. This fact means that 
the nature of the cations of the presented salts strongly affects the local environment since to a higher asymmetry parameter the luminescent center is located more apart from a centrosymmetric geometry.

To compare the luminescence intensities of $\mathbf{1}$ and [Chol][Eu(fod $\left.)_{4}\right]$, the ratio $\left(\mathrm{R}_{21}\right)$ between the area under the emission curve of the hypersensitive ${ }^{5} \mathrm{D}_{0} \rightarrow{ }^{7} \mathrm{~F}_{2}$ and of the magnetic dipole allowed ${ }^{5} \mathrm{D}_{0} \rightarrow{ }^{7} \mathrm{~F}_{1}$ were determined. For $\mathbf{1}$ we found a value for $\mathrm{I}\left({ }^{5} \mathrm{D}_{0} \rightarrow{ }^{7} \mathrm{~F}_{2}\right) / \mathrm{I}\left({ }^{5} \mathrm{D}_{0} \rightarrow{ }^{7} \mathrm{~F}_{1}\right)$ of 15.5 and for the [Chol] $\left[\mathrm{Eu}(\mathrm{fod})_{4}\right]$ a much lower $\mathrm{R}_{21}$ value of 5.6; to a higher ratio corresponds a more intense red emission. These $R_{21}$ values are much higher than the value 0.67 of a centrosymmetric europium (III) complex [27], meaning that the $\mathrm{Eu}(\mathrm{III})$ ion is in a low site symmetry without an inversion center in the anionic $\left[\mathrm{Eu}(\mathrm{fod})_{4}\right]^{-}$core.

As can be observed, the ${ }^{5} \mathrm{D}_{0} \rightarrow{ }^{7} \mathrm{~F}_{2}$ line of [Chol] $\left[\mathrm{Eu}(\mathrm{fod})_{4}\right]$ is much narrower than the majority obtained for other complexes, reflecting, as was said previously a $\mathrm{I}\left({ }^{5} \mathrm{D}_{0} \rightarrow{ }^{7} \mathrm{~F}_{2}\right) / \mathrm{I}\left({ }^{5} \mathrm{D}_{0} \rightarrow{ }^{7} \mathrm{~F}_{1}\right)$ ratio of 5.6.

\subsubsection{Temperature Effect}

We referred above that [Chol] [Eu(fod $\left.)_{4}\right]$ [25] presented an unusual thermochromic behavior, similar to what was previously reported for the ionic liquid $\left[\mathrm{P}_{6,6,6,14}\right]\left[\mathrm{Eu}(\mathrm{fod})_{4}\right][14]$ which changed from light yellow to deep red around $80^{\circ} \mathrm{C}$.

Figure 3 a displays the absorption and the excitation spectra of $\mathbf{1}$ acquired at ambient temperature monitoring the emission at their corresponding maxima of $612 \mathrm{~nm}$.
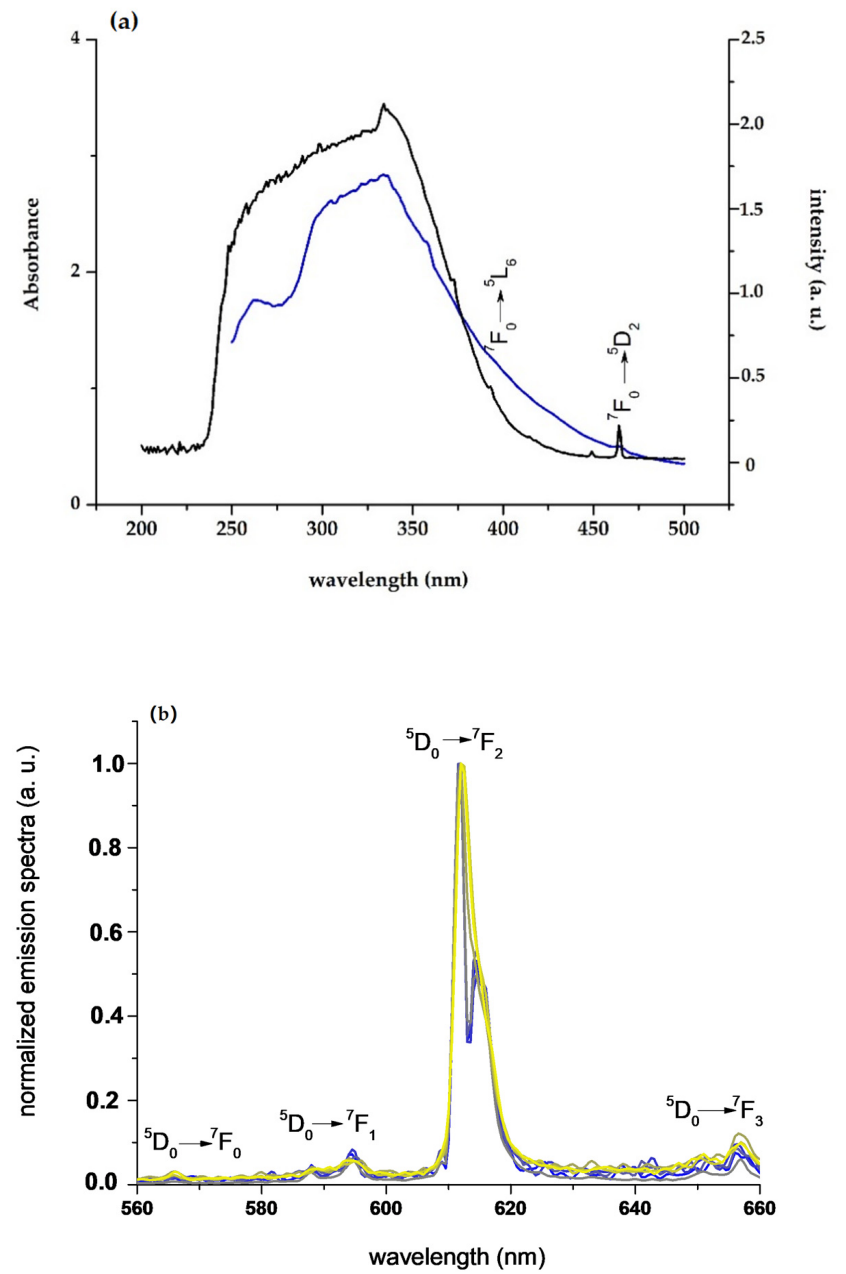

Figure 3. (a) Absorption spectra of $\mathbf{1}$ (blue line) and excitation spectra (black line) monitored with $\lambda_{\mathrm{em}}=612 \mathrm{~nm}$. (b) Normalized emission spectra of 1 relative to the maximum of ${ }^{5} \mathrm{D}_{0} \rightarrow{ }^{7} \mathrm{~F}_{2}$ transition band $\left(25^{\circ} \mathrm{C}\right.$ ), from 25 (blue line) to $55^{\circ} \mathrm{C}$ (yellow line) with a $5{ }^{\circ} \mathrm{C} \cdot \mathrm{min}^{-1}$ step size between each measurement with $\lambda_{\text {exc. }}=345 \mathrm{~nm}$. 
Both spectra display a large broad band ascribed to the excited states of the ligands (260-450 nm), with one small peak around 393 [28]. A line at ca. $465 \mathrm{~nm}$ is assigned to the ${ }^{7} \mathrm{~F}_{0} \rightarrow{ }^{5} \mathrm{D}_{2} \mathrm{Eu}$ (III) intra- $4 \mathrm{f}^{6}$ transition and is observable in both the absorption and excitation spectra.

The ${ }^{5} \mathrm{D}_{0} \rightarrow{ }^{7} \mathrm{~F}_{0}$ is a forbidden transition, showing very week emission. The ${ }^{5} \mathrm{D}_{0} \rightarrow{ }^{7} \mathrm{~F}_{1}$ peak splitting was maintained unaltered during all temperature range (Figure $3 \mathrm{~b}$ ). This transition is a magnetic dipole (MD) transition and as such is largely independent of the environment of the Eu (III) ion. The total intensity of this transition was then used to calibrate the intensity of the luminescence spectra at different temperatures (Figure 4).

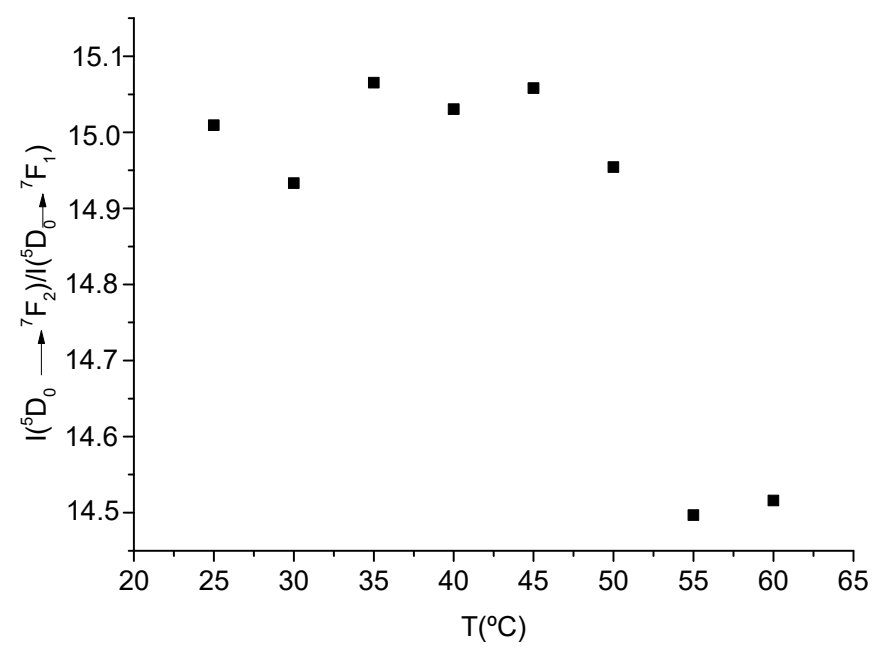

Figure 4. Temperature dependent total integrated intensity of ${ }^{5} \mathrm{D}_{0} \rightarrow{ }^{7} \mathrm{~F}_{2}$ transition relative to the ${ }^{5} \mathrm{D}_{0} \rightarrow{ }^{7} \mathrm{~F}_{1}$ transition band between 25 and $55^{\circ} \mathrm{C}$.

For $\mathbf{1}$ it was not observed any thermochromism in the visible range and upon heating the emission spectra profile was maintained constant until it starts to melt at temperatures close to $60^{\circ} \mathrm{C}$ (Figure $3 \mathrm{~b}$ ). Even though, the emission spectra of $\mathbf{1}$ was monitored from room temperature, with a $5{ }^{\circ} \mathrm{C}$ degree step between 25 and $60^{\circ} \mathrm{C}$ (Figure 4).

Complex 1 melt at $60{ }^{\circ} \mathrm{C}$ and no ratiometric relations were found with temperature increase. A low melting is most likely a result of the aliphatic long chain which also reduces the cation-anion interactions, possibly due to steric effects.

The ${ }^{5} \mathrm{D}_{0}$ decay curves of the $\mathrm{Eu}(\mathrm{III})$, irrespective of the emission line detected, the excitation wavelength selected and the temperature, can always be fitted by a single exponential function giving lifetime values $0.63 \pm 0.01 \mathrm{~ms}$, for 1 (Figure S5).

The thermal properties of $\mathbf{1}$ and $\mathbf{1 / P S U}$ were examined using differential scanning calorimetry (DSC) and thermogravimetry (TG) on powder samples. By the TG analysis (Figure S3), compound 1 is stable until close to $170{ }^{\circ} \mathrm{C}$, while the PSU matrix only starts to degrade after $450^{\circ} \mathrm{C}$. By the DSC analysis (Figure S4), the melting of 1 occurs at $59.5^{\circ} \mathrm{C}$ (with an onset at $53.3^{\circ} \mathrm{C}$ and an offset at $62.7^{\circ} \mathrm{C}$ ) and this transition is visible in 1/PSU as a "flattened" region in the DSC curve.

\subsection{Characterization of $1 / P S U$ and $[\mathrm{Chol}]\left[E u(f o d)_{4}\right] / P S U$ with $10 \%(w / w)$ of the Complex}

Here, we summarize the spectral evidence of Eu (III) energy transfer in PSU hybrids incorporating both $\mathbf{1}$ and [Chol][Eu(fod $\left.)_{4}\right]$ in $10 \%(w / w)$ in polysulfone. The schematic representation of the PSU polymer is presented in Figure 5. Preparation, photophysical and thermochromic properties of these functionalized materials were never reported before. 


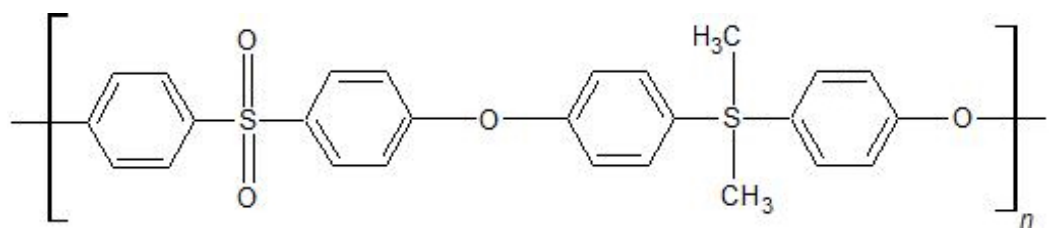

Figure 5. Schematic representation of the PSU polymer.

\subsubsection{Photophysical Characterization}

The luminescence decay lifetimes $(\tau)$ and the quantum efficiency $(\Phi)$ for the hybrid materials were also evaluated as a measure of the efficiency of the emission process (Table 2). The luminescence lifetimes $(\tau)$ of the film with $10 \%$ of Eu (III) complex is $0.63 \mathrm{~ms}$, identical to what was found for 1 (Figures S5 and S6). According with Figures S5 and S6, both the hybrid film and the free complex exhibited a single exponential decay with the same lifetime value suggesting the same radiative decay pathway within the imbibed molecule. The absorption and excitation spectra of pristine PSU is presented in Figure S7.

Table 2. Emission lifetime ( $\tau$, ms, Figures S5 and S6) and absolute emission quantum yield ( $\Phi, \%$, Figure S8) of $\mathbf{1}$ and [Chol][Eu(fod) $)_{4}$ ] and confined polysulfone films with $10 \%$ loading.

\begin{tabular}{ccccc}
\hline $\boldsymbol{-}$ & $\mathbf{1}$ & $\mathbf{1} / \mathrm{PSU}$ & {$[\mathrm{Chol}]\left[\mathrm{Eu}\left(\text { fod }_{4}\right]_{[}[25]\right.$} & $\left.[\text { Chol][Eu(fod })_{4}\right] /$ PSU \\
\hline$\tau(\mathrm{ms})$ & 0.63 & 0.62 & 1.26 & 0.87 \\
$\Phi(\%)$ & 100 & 21 & 81 & 24 \\
\hline
\end{tabular}

3.2.2. Thermochromism with Temperature-Responsive Ratiometric Behavior of 1/PSU and $[\mathrm{Chol}]\left[\mathrm{Eu}(\mathrm{fod})_{4}\right] / \mathrm{PSU}$

Similar to the observed for 1, the doped membrane 1/PSU presents a reduction in the emission intensity of Eu (III) that is not accompanied by any significant changes in its profile (Figure 6a). 1/PSU film presented a usually observed and commonly reported temperature-dependent luminescence intensity with a linear fit from 60 to $100^{\circ} \mathrm{C}$ (Figure 6b).

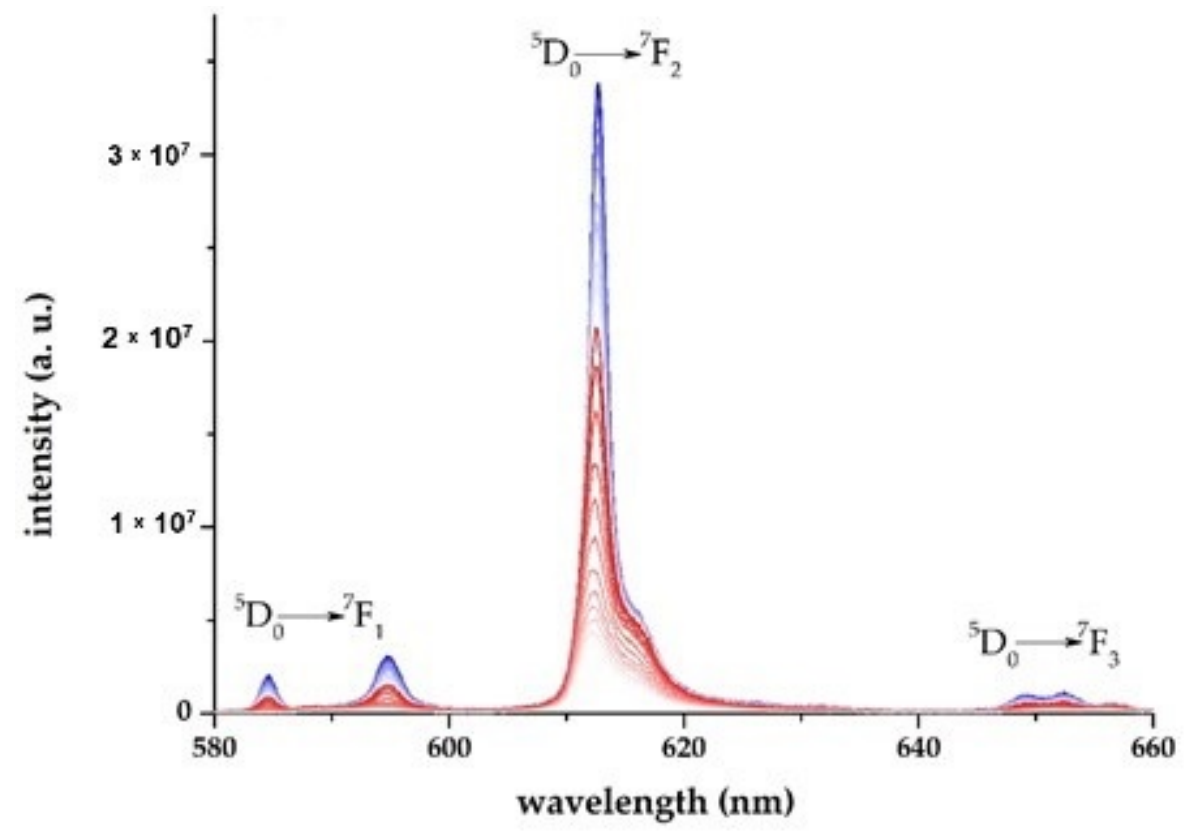

(a)

Figure 6. Cont. 


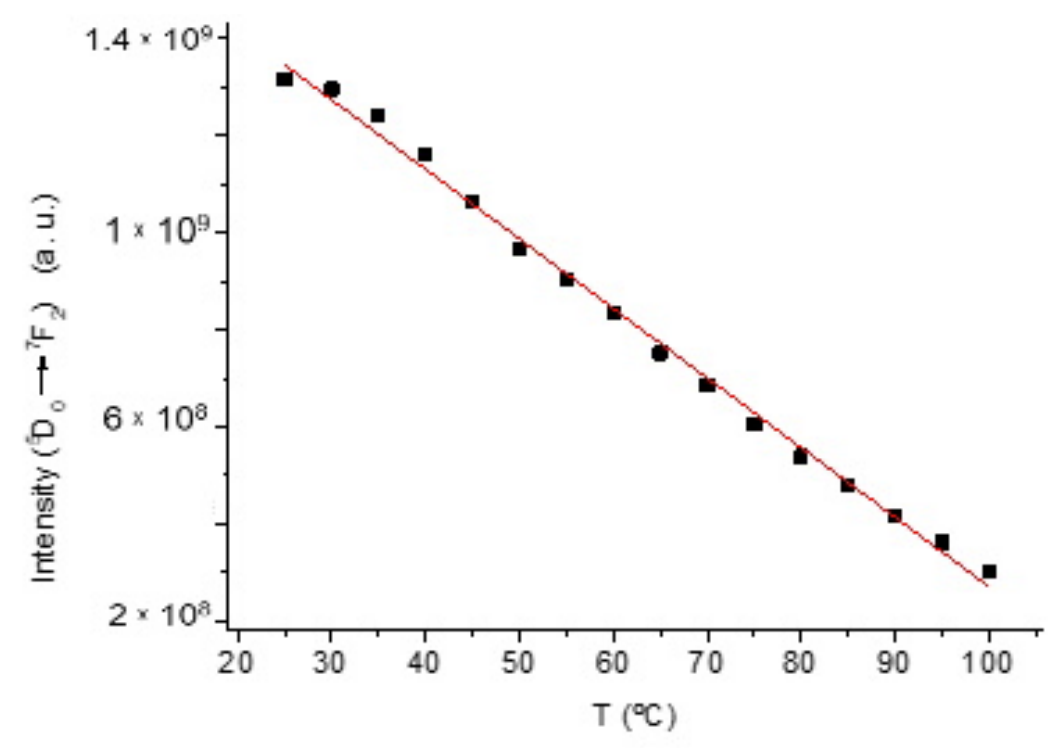

(b)

Figure 6. (a) emission spectra of $\mathbf{1} / \mathbf{P S U}$ at different temperatures upon excitation at $320 \mathrm{~nm}$. Most intense blue line at room temperature, less intense red line acquisition ate $135{ }^{\circ} \mathrm{C} ;(\mathbf{b})$ total intensity of ${ }^{5} \mathrm{D}_{0} \rightarrow{ }^{7} \mathrm{~F}_{2}$ transition band between 25 and $100{ }^{\circ} \mathrm{C}$ with $5^{\circ} \mathrm{C}$ step, $\mathrm{y}=-1.43 \mathrm{x}+1.70\left(\mathrm{r}^{2}=0.99\right)$.

In Figure 7a we present the emission spectra of [Chol][Eu(fod) $\left.)_{4}\right] / \mathbf{P S U}$ with $10 \%$ loading of Eu (III) complex when exposed at temperatures between 25 and $160^{\circ} \mathrm{C}$. The feature that allows the ratiometric relation found and presented in Figure $7 \mathrm{~b}$ is the relative increase of the intensity of the shoulder at $616 \mathrm{~nm}$, from low to higher intensities as the temperature increases. Figure $6 \mathrm{~b}$ represents the relations found between the total integrated intensity of the ${ }^{5} \mathrm{D}_{0} \rightarrow{ }^{7} \mathrm{~F}_{2}$ relative to the total intensity of the ${ }^{5} \mathrm{D}_{0} \rightarrow{ }^{7} \mathrm{~F}_{1}$ magnetic transition for the [Chol][Eu(fod) $\left.{ }_{4}\right] /$ PSU membrane. A polynomial fit can be used to relate ratiometrically the emission bands intensity with temperature, with the equation $y=0.875+0.597 x-0.024 x^{2}+4.66 \times 10^{-4} x^{3}$. Above $100^{\circ} \mathrm{C}$ we did not consider the ratiometric relation due to a random variation of the ratio, eventually caused by reduction of chemical stability of the $\mathrm{Eu}$ (III) complex.

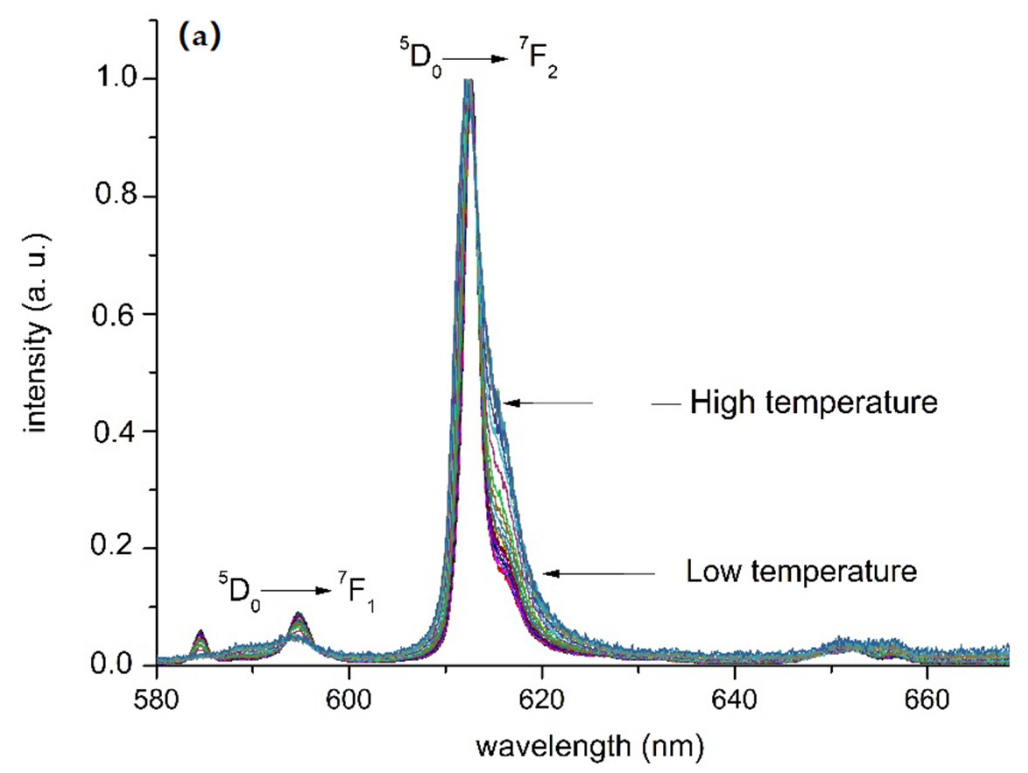

Figure 7. Cont. 


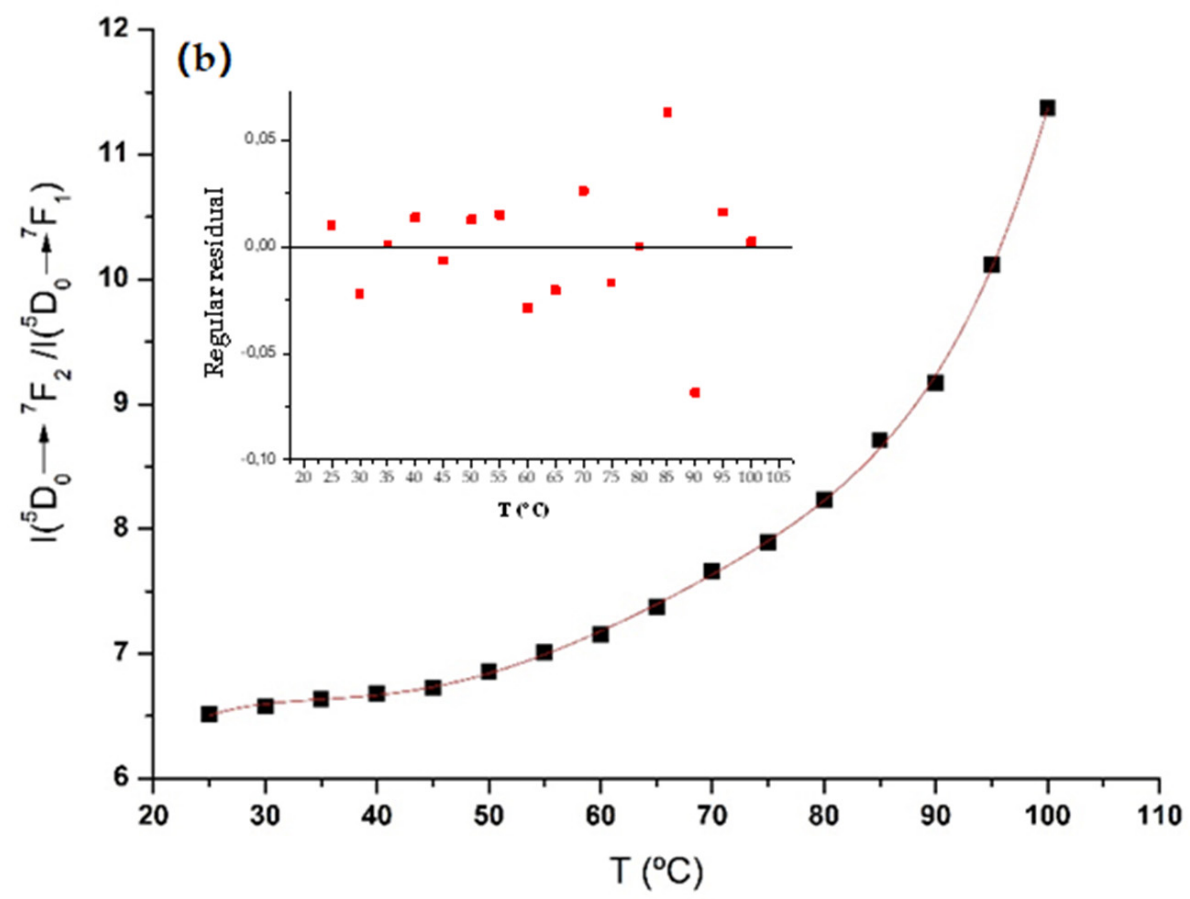

Figure 7. (a) emission spectra of [Chol][Eu(fod) 4 ]/PSU at different temperatures (from 25 to $160{ }^{\circ} \mathrm{C}$ ) with $\lambda_{\text {exc }}=325 \mathrm{~nm}$; (b) Thermochromic response of [Chol][Eu(fod) 4$] /$ PSU film from 25 to $100{ }^{\circ} \mathrm{C}$ with polynomial fit $y=0.875+0.597 x-0.024 x^{2}+4.66 \times 10^{-4} x^{3}, r^{2}=0.99$. Inset: regular residual associated with each measurement.

\subsubsection{Images of $1 / \mathrm{PSU}$ and [Chol][Eu(fod $\left.)_{4}\right] / \mathrm{PSU} 10 \%(w / w)$}

$\mathrm{N}$-cetylpyridinium chloride, $\mathrm{C}_{16} \mathrm{PyrCl}$, is classified as a cationic surfactant, and the long structures visible in the SEM image of 1/PSU (Figure 8b) are attributed to the formation of micelles [29]. Despite the long $\mathrm{C}_{16}$ aliphatic chains the hydrophilic character of $\mathbf{1 / P S U}$ film is higher than found for [Chol][Eu(fod) $\left.)_{4}\right] / P S U$ as was confirmed by the results obtained from the measurements of the water contact angles (Table 3). Lower contact angles correspond to good adhesiveness, good wettability, and high solid surface free energy. 


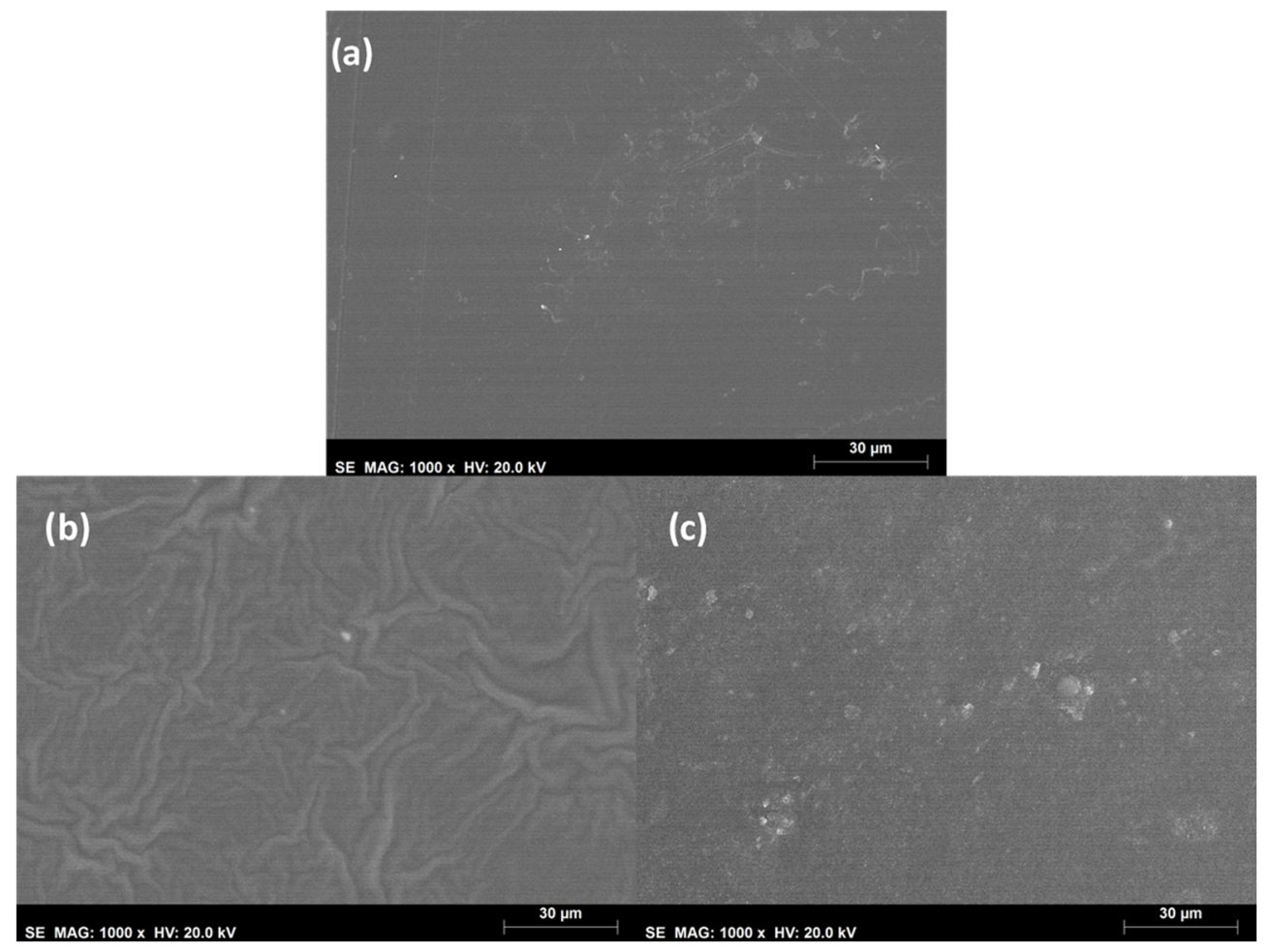

Figure 8. (a) SEM image of top surface PSU with 1000× magnification. (b) SEM image of top surface of 1/PSU $(10 \% w / w)$ nanocomposite with $1000 \times$ magnification showing micelles formed by $\mathbf{1}$. (c) SEM image of top surface of [Chol][Eu(fod) $\left.)_{4}\right] /$ PSU $(10 \% w / w)$ nanocomposite with $1000 \times$ magnification.

Table 3. Water contact angles of pristine PSU and modified PSU membranes with $10 \%$ of $\mathbf{1}$ and $[\mathrm{Chol}]\left[\mathrm{Eu}(\mathrm{fod})_{4}\right]$.

\begin{tabular}{cccc}
\hline- & PSU & 1/PSU & [Chol][Eu(fod) $)_{4}$ /PSU \\
\hline $\begin{array}{c}\text { Water contact } \\
\text { angle }\left(^{\circ}\right)\end{array}$ & 66 & 79 & 84 \\
\hline
\end{tabular}

Confining $10 \%$ of $\mathbf{1}$ or [Chol][Eu(fod $\left.)_{4}\right]$ induced, according with the commonly known experience [30], increase of the water contact angle of the hybrid membrane can be attributed to the hydrophobic nature of the guest material.

Sanz-Medel and co-workers also suggested that both electrostatic and hydrophobic interactions concurrently promote fluorescence yield in micellar solutions [31].

Figure 9 shows the color of the studied membranes under UV light at 25, 50, 75 and $100{ }^{\circ} \mathrm{C}$.

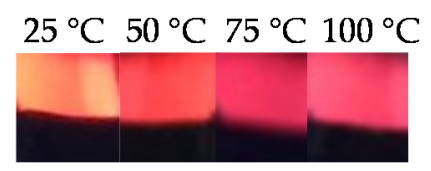

(a)

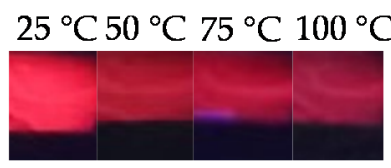

(b)

Figure 9. Images of (a) 1/PSU and (b) $[\mathrm{Chol}]\left[\mathrm{Eu}(\mathrm{fod})_{4}\right] / \mathrm{PSU}$ under $366 \mathrm{~nm}$ UV lamp at different temperatures. 


\section{Discussion}

The experimented cations induced significant fluorescence changes in the emissive specie which provide different sensing possibilities performed by the anionic $\left[\mathrm{Eu}(\mathrm{fod})_{4}\right]^{-}$core. Specific properties of the cholinium cation, that allow thermochromism in the solid state in combination with the [Eu(fod $\left.)_{4}\right]^{-}$ anion, are not present in the N-cetylpyridinium as a counter-ion. Confinement in a polymer film of polysulfone maintains the presence of a ratiometric behavior although the linearity previously observed for the $[\mathrm{Chol}]\left[\mathrm{Eu}(\text { fod })_{4}\right]$ is lost and instead a polynomial relation is established in the emissive film.

\section{Conclusions}

The experimented cations induced significant fluorescence changes in the emissive specie which may provide several sensing possibilities performed by the anionic $\left[\mathrm{Eu}(\mathrm{fod})_{4}\right]^{-}$core which can be preserved after confinement in a polysulfone matrix. In opposition to the observed previously, higher amount of $\mathrm{Eu}$ (III) complex allows establishing a relation between temperature and the ratio between two transition bands of a thin film of [Chol][Eu(fod $\left.)_{4}\right] / P S U$. The unique thermochromic behavior discussed here deserves further studies in the near future and we intend to perform further work using different materials for biological applications.

Supplementary Materials: The following are available online at http://www.mdpi.com/1996-1944/13/23/5394/s1, Figure S1: ESI-MS analysis of compound 1 in acetonitrile, positive mode, Figure S2. ESI-MS analysis of compound 1 in acetonitrile, negative mode, Figure S3: Thermogravimetric profile of PSU (green), 1-PSU (blue) and 1 (red), Figure S4: Differential Scanning Calorimetry analysis of $\mathbf{1}$ (red) and 1/PSU (blue), Figure S5. Luminescence decay curves of 1 at emission maxima of $612 \mathrm{~nm}$, Figure S6: Luminescence decay curves of 1/PSU at emission maxima of $612 \mathrm{~nm}$, Figure S7. Absorption (up) and excitation (down) spectra of pristine PSU, Figure S8. Schematic representation of the three-measurement approach; L (up) refers to excitation and P (down) to emission: La empty sphere, Lb sample out of the beam, Lc sample in the path of the incident beam.

Author Contributions: Conceptualization, B.M. and C.C.L.P.; formal analysis, M.O., J.P.L., M.H.C., B.M. and C.C.L.P.; investigation, M.O., J.P.L., M.H.C., B.M. and C.C.L.P.; methodology, M.O., B.M. and C.C.L.P.; supervision, B.M. and C.C.L.P.; writing-original draft, C.C.L.P.; writing-review and editing, B.M. and C.C.L.P. All authors have read and agreed to the published version of the manuscript.

Funding: This work was supported by the Associated Laboratory for Sustainable Chemistry-Clean Processes and Technologies-LAQV which is financed by national funds from FCT/MEC (UID/QUI/50006/2019) and co-financed by the ERDF under the PT2020 Partnership Agreement (POCI-01-0145-FEDER-007265) The NMR spectrometers are part of The National NMR Facility, supported by Fundação para a Ciência e a Tecnologia (RECI/BBB-BQB/0230/2012). This work has been supported by Fundação para a Ciência e a Tecnologia through the contract $n^{\circ}$ IST-ID/077/2018 (Bernardo Monteiro), SFRH/BD/120985/2016 (Mani Outis), contract no IST-ID/076/2018 (M. Helena Casimiro) and SFRH/BPD/120599/2016 (João Avó). C.C.L.P. thanks to Fundação para a Ciência e a Tecnologia, MCTES, for the Norma transitória DL 57/2016 Program Contract. Centro de Química Estrutural (CQE) acknowledges the financial support of Fundação para a Ciência e Tecnologia (UIDB/00100/2020). Centro de Ciências e Tecnologias Nucleares (C2TN) acknowledges the financial support of Fundação para a Ciência e Tecnologia by FEDER funds through the COMPETE 2020 Program UIDB/04349/2020.

Conflicts of Interest: The authors declare no conflict of interest.

\section{References}

1. Bednarkiewicz, A.; Marciniak, L.; Carlos, L.D.; Jaque, D. Standardizing luminescence nanothermometry for biomedical applications. Nanoscale 2020, 12, 14405-14421. [CrossRef] [PubMed]

2. Brites, C.D.S.; Balabhadra, S.; Carlos, L.D. Lanthanide-Based Thermometers: At the Cutting-Edge of Luminescence Thermometry. Adv. Opt. Mater. 2018, 7, 1801239. [CrossRef]

3. Kobayashi, H.; Ogawa, M.; Alford, R.; Choyke, P.L.; Urano, Y. New Strategies for Fluorescent Probe Design in Medical Diagnostic Imaging. Chem. Rev. 2010, 110, 2620-2640. [CrossRef] [PubMed]

4. Jaque, D.; del Rosal, B.; Rodriguez, E.M.; Maestro, L.M.; Haro-Gonzalez, P.; Sole, J.G. Fluorescent nanothermometers for intracellular thermal sensing. Nanomedicine 2014, 9, 1047-1062. [CrossRef] [PubMed]

5. Weaver, J.B. Bioimaging: Hot nanoparticles light up cancer. Nat. Nanotechnol 2010, 5, 630-631. [CrossRef]

6. Liang, Z.; Qin, F.; Zheng, Y.; Zhang, Z.; Cao, W. Noncontact thermometry based on downconversion luminescence from $\mathrm{Eu}^{3+}$ doped $\mathrm{LiNbO}_{3}$ single crystal. Sens. Actuator. A Phys. 2016, 238, 215-219. [CrossRef] 
7. Đačanin, L.R.; Dramićanin, M.D.; Lukić-Petrović, S.R.; Petrović, D.M.; Nikolić, M.G. Eu ${ }^{3+}$ doped $\mathrm{YNbO}_{4}$ phosphor properties for fluorescence thermometry. Radiat. Meas. 2013, 56, 143-146. [CrossRef]

8. Nikolić, M.G.; Al-Juboori, A.Z.; Dordević, V.; Dramićanin, M.D. Temperature luminescence properties of $\mathrm{Eu}^{3+}$-doped $\mathrm{Gd}_{2} \mathrm{O}_{3}$ phosphors. Phys. Scr. 2013, T157, 014056. [CrossRef]

9. Ćirić, A.; Stojadinović, S.; Dramićanin, M.D. Luminescence intensity ratio thermometry and judd-ofelt analysis of $\mathrm{TiO}_{2}: \mathrm{Eu}^{3+}$. Opt. Mater. 2018, 85, 261-266. [CrossRef]

10. Nikolić, M.G.; Jovanović, D.J.; Dramićanin, M.D. Temperature dependence of emission and lifetime in Eu ${ }^{3+}$ and $\mathrm{Dy}^{3+}$-doped $\mathrm{GdVO}_{4}$. Appl. Opt. 2013, 52, 1716-1724. [CrossRef]

11. Nikolić, M.G.; Lojpur, V.; Antić, Ž.; Dramićanin, M.D. Thermographic properties of a $\mathrm{Eu}^{3+}$-doped $\left(\mathrm{Y}_{0.75} \mathrm{Gd}_{0.25}\right)_{2} \mathrm{O}_{3}$ nanophosphor under UV and x-ray excitation. Phys. Scr. 2013, 87, 055703. [CrossRef]

12. Meert, K.W.; Morozov, V.A.; Abakumov, A.M.; Hadermann, J.; Poelman, D.; Smet, P.F. Energy transfer in Eu ${ }^{3+}$ doped scheelites: Use as thermographic phosphor. Opt. Express 2014, 22, A961-A974. [CrossRef] [PubMed]

13. Lojpur, V.; Ćulubrk, S.; Medić, M.; Dramicanin, M. Luminescence properties of $\mathrm{Eu}^{3+}$ doped $\mathrm{YBO}_{3}$ for temperature sensing. J. Lumin. 2016, 170, 467. [CrossRef]

14. Monteiro, B.; Outis, M.; Cruz, H.; Leal, J.P.; Laia, C.A.T.; Pereira, C.C.L. A thermochromic europium(III) room temperature ionic liquid with thermally activated anion-cation interactions. Chem. Commun. 2017, 53, 850-853. [CrossRef] [PubMed]

15. Adati, R.D.; Monteiro, J.H.S.K.; Cardoso, L.P.; de Oliveira, D.H.; Jafelicci Jr., M.; Davolos, M.R. The Influence of Different Ammonium Cations on the Optical Properties of Tetrakis GdIII and EuIII Complexes. J. Braz. Chem. Soc. 2019, 30, 1707-1716. [CrossRef]

16. Lyszczeka, R.; Gil, M.; Głuchowska, H.; Podkościelna, B.; Lipke, A.; Mergo, P. Hybrid materials based on PEGDMA matrix and europium (III) carboxylates-thermal and luminescent investigations. Eur. Polym. J. 2018, 106, 318-328. [CrossRef]

17. Yang, P.; Zhang, S.; Chen, X.; Liu, X.; Wang, Z.; Li, Y. Recent developments in polydopamine fluorescent nanomaterials. Mater. Horiz. 2020, 7, 746-761. [CrossRef]

18. Aguiar, F.P.; Costa, I.F.; Espínola, J.G.P.; Faustino, W.M.; Moura, J.L.; Brito, H.F.; Paolini, T.B.; Felinto, M.C.F.C.; Teotonio, E.E.S. Luminescent hybrid materials functionalized with lanthanide ethylenodiaminotetraacetate complexes containing $\beta$-diketonate as antenna ligands. J. Lumin. 2016, 170, 538-546. [CrossRef]

19. Leyre, S.; Coutino-Gonzalez, E.; Joos, J.J.; Ryckaert, J.; Meuret, Y.; Poelman, D.; Smet, P.F.; Durinck, G.; Hofkens, J.; Deconinck, G.; et al. Absolute determination of photoluminescence quantum efficiency using an integrating sphere setup. Rev. Sci. Instrum. 2014, 85, 123115. [CrossRef]

20. Bunzli, J.-C.G.; Piguet, C. Taking advantage of luminescent lanthanide ions. Chem. Soc. Rev. 2005, 34, 1048-1077. [CrossRef]

21. Binnemans, K. Interpretation of Eu(III) spectra. Coord. Chem. Rev. 2015, 295, 1-45. [CrossRef]

22. Görller-Walrand, C.; Fluyt, L.; Ceulemans, A.; Carnall, W.T. Magnetic dipole transitions as standards for Judd-Ofelt parametrization in lanthanide spectra. J. Chem. Phys. 1991, 95, 3099-3106. [CrossRef]

23. Tang, S.-F.; Lorbeer, C.; Wang, X.; Ghosh, P.; Mudring, A.-V. Highly Luminescent Salts Containing Well-Shielded Lanthanide-Centered Complex Anions and Bulky Imidazolium Countercations. Inorg. Chem. 2014, 53, 9027-9035. [CrossRef] [PubMed]

24. Mech, A.; Karbowiak, M.; Gorller-Walrand, C.; Van Deun, R. The luminescence properties of three tetrakis-dibenzoylmethane europium (III) complexes with different counter ions. J. Alloys Compd. 2008, 451, 215-219. [CrossRef]

25. Outis, M.; Laia, C.A.T.; Oliveira, M.C.; Monteiro, B.; Pereira, C.C.L. A Europium(III) Complex with an Unusual Anion-Cation Interaction: A Luminescent Molecular Thermometer for Ratiometric Temperature Sensing. ChemPlusChem 2020, 85, 580-586. [CrossRef] [PubMed]

26. Binnemans, K. Rare-Earth Beta-Diketonates, Chapter 225. In Handbook on the Physics and Chemistry of Rare Earths, 2nd ed.; Gschneidner, K.A., Jr., Bünzli, J.-C.G., Pecharsky, V.K., Eds.; Elsevier: Amsterdam, The Netherlands, 2005; Volume 35.

27. Fu, F.; Sá-Ferreira, R.A.; Silva, N.J.O.; Fernandes, A.J.; Ribeiro-Claro, P.; Goncalves, I.S.; de Zea Bermudez, V.; Carlos, L.D. Structure-photoluminescence relationship in Eu(III) $\beta$-diketonate-based organic-inorganic hybrids. Influence of the synthesis method: Carboxylic acid solvolysis versus conventional hydrolysis. J. Mater. Chem. 2005, 15, 3117-3125. [CrossRef] 
28. Zhou, L.; Pang, Q.; Gong, F.; Sun, J.; Wang, W. Photoluminescence properties of a novel phosphor $\mathrm{CaB}_{2} \mathrm{O}_{4}$ :Eu $\mathrm{Eu}^{3+}$ under NUV excitation. Luminescence 2009, 24, 363-366.

29. Ghosh, A.; Saha, R.; Mukherjee, K.; Sar, P.; Ghosh, S.K.; Malik, S.; Bhattacharyya, S.S.; Saha, B. Rate enhancement via micelle encapsulation for room temperature metal catalyzed Ce(IV) oxidation of p-chlorobenzaldehyde to $p$-chlorobenzoic acid in aqueous medium at atmospheric pressure. J. Mol. Liq. 2014, 190, 81-93. [CrossRef]

30. Shaw, D.J. Introduction to Colloid and Surface Chemistry, 3rd ed.; Butter-Worth and Co. (Publishers) Ltd.: London, UK, 1980; p. 134.

31. Sanz-Medel, A.; de la Campa, R.F.; Garcia Alonso, J.I. Metal Chelate Fluorescence Enhancement in Micellar Media: Mechanisms of Surfactant Action. Analyst 1987, 112, 493-497. [CrossRef]

Publisher's Note: MDPI stays neutral with regard to jurisdictional claims in published maps and institutional affiliations.

(C) 2020 by the authors. Licensee MDPI, Basel, Switzerland. This article is an open access article distributed under the terms and conditions of the Creative Commons Attribution (CC BY) license (http://creativecommons.org/licenses/by/4.0/). 